\title{
Securing the Conservation of Biodiversity across Administrative Levels and Spatial, Temporal, and Ecological Scales Research Needs and Approaches of the SCALES Project
}

\begin{abstract}
Human actions generate various pressures on biodiversity. It has proven very difficult to match the scales of social and economic demands, pressures, impacts, scientific analysis, and governmental responses. However, biodiversity conservation can be effective only if management measures fit the ecological scales of the impacts they aim to address.
\end{abstract}

Klaus Henle, William Kunin, Oliver Schweiger, Dirk S. Schmeller, Vesna Grobelnik, Yiannis Matsinos, John Pantis, Lyubomir Penev, Simon G. Potts, Irene Ring, Jukka Similä, Joseph Tzanopoulos, Sybille van den Hove, Michel Baguette, Jean Clobert, Laurent Excoffier, Erik Framstad, Małgorzata Grodzińska-Jurczak, Szabolcs Lengyel, Pascal Marty, Atte Moilanen, Emmanuelle Porcher, David Storch, Ingolf Steffan-Dewenter, Martin T. Sykes, Martin Zobel, Josef Settele
Securing the Conservation of Biodiversity across Administrative Levels and Spatial, Temporal, and Ecological Scales - Research Needs and Approaches of the SCALES Project

GAIA 19/3 (2010): 187-193

\begin{abstract}
Biodiversity conservation measures and biological processes often do not match in scale. The EU funded project SCALES (Securing the Conservation of biodiversity across Administrative Levels and spatial, temporal, and Ecological Scales) is intended to solve this challenge. SCALES analyses how selected pressures (climate change, habitat loss, fragmentation, disturbance), their drivers, and their impacts on biodiversity change with spatial and temporal scale. The project develops methods for a better understanding of scaling properties of biological processes from the genetic level to populations, communities, and ecosystem functions. SCALES also seeks ways to integrate the issue of scale into policy, decision-making, and biodiversity management, focusing on networks of protected areas, regional connectivity, and biodiversity monitoring.
\end{abstract}

Keywords

anthropogenic drivers, biodiversity impacts, climate change, fragmentation, policy instruments, scale, science-policy interface

\section{Importance and Challenges of Scale in Biodiversity Conservation}

The continued loss of biodiversity is intimately linked to the issue of scale; the scale at which climate change operates contrasts that at which habitat loss, fragmentation, and disturbance do. Biological processes are also scale-dependent and habitat requirements of species may even reverse with scale but this is often ignored (Altmoos and Henle 2010). For example, species diversity and whether a species is regarded as rare or abundant and whether it declines or increases often depend on the scale at which the analysis takes place (Debinsky et al. 2001, Hartley and Kunin 2003). Similarly, the sensitivity of species to fragmentation depends on the scale at which fragmentation occurs and how this scale matches the scale of the area requirement and dispersal of species (Henle et al. 2004).

Socio-economic drivers of change and their impacts on biodiversity and ecosystems likewise operate at various administrative and temporal scales (Mathevet and Mauchamp 2005). Similarly, conservation priorities often change across administrative levels and ignorance of scale may lead to inappropriate allocation of limited conservation resources, e. g., when countries focus conservation resources on species that just reach into their territories and that therefore are rare at the scale of the country but may be very
Contact: PD Dr. Klaus Henle | Helmholtz Centre for Environmental Research - UFZ | Department of Conservation Biology |

Permoserstr. 15 | 04318 Leipzig | Germany | Tel.: +49 3412351270 | E-Mail: klaus.henle@ufz.de

Dr. Simon G. Potts | University of Reading | School of Agriculture, Policy and Development | Reading | United Kingdom | E-Mail:

s.g.potts@reading.ac.uk
Assoc. Prof. Małgorzata Grodzińska-Jurczak | Jagiellonian University | Institute of Environmental Sciences | Environmental Education Research Team | Kraków | Poland | E-Mail: m.grodzinska-jurczak@uj.edu.pl

(C) 2010 K. Henle et al.; licensee oekom verlag.

This is an Open Access article distributed under the terms of the Creative Commons Attribution License (http://creativecommons.org/licenses/by/3.0), which permits unrestricted use, distribution and reproduction in any medium, provided the original work is properly cited. 
abundant and widespread at the scale of their European distribution (Schmeller et al. 2008 a). For example, the common wall lizard (Podarcis muralis) is rare in most states of Germany and often a target species of conservation activities but it is extremely common in Italy (Henle et al. 1999, Steinicke et al. 2002).

There is a long history of disappointments in policy, management, and assessment arising from scale mismatches in socialecological systems (Cumming et al. 2006). Cormorant (Phalacrocorax carbo) conservation and the intensive conflicts with fisheries are a well-publicised example. Some countries like France have been trying to limit the population of cormorants in their territory by large-scale culling; others like some German states have permitted local scaring or shooting. These ongoing efforts to limit the cormorant population are, however, uncoordinated, damage persists, and management has been unsuccessful (Behrens et al. 2008). In addition, there is considerable debate on whether cormorants should be managed at all, with many fishers and anglers strongly pressuring for it, and nature conservationists, especially ornithologists, strongly opposing it. One of the main motivations for opposition is the fear that any management could endanger the species again because it would not be possible to control management such that it matches the ecological scale of cormorant dynamics. Population modelling shows that inadequate control measures could in fact rapidly lead to an endangerment of the cormorant. As cormorants are mobile at the scale of Europe, management needs to be coordinated at the European level (Behrens et al. 2008).

Mismatches between ecological scale and governance levels are also common in networks of protected areas. The designation of Natura 2000 sites in the Larzac region, south-east of the French Massif Central, is an example (Lepart and Marty 2005). An administrative border crosses this natural area characterised by seminatural calcareous grasslands threatened by tree and shrub encroachment. Almost all the area to the south, belonging to the Herault Département in the Languedoc-Roussillon region, was included in the Natura 2000 network (site FR9101385), whereas in the northern part of the plateau, belonging to the Aveyron Département in the Midi-Pyrénées region, only a small area with almost no agricultural activities - was designated (site FR7300864).

Mismatches between processes of biodiversity change and biodiversity management can be avoided only if we understand how impacts from human actions, driven by social and economic forces, change with scale. For example, gross domestic product and agricultural conversion are not uniformly distributed across Europe and often not within particular member states (Le Gallo and Ertur 2003, Henle et al. 2008). These driving forces generate various pressures on biodiversity, such as climate change and habitat loss, fragmentation, and disturbance. The pressures in turn impact biodiversity at various levels of biological organisation. All these factors act at characteristic scales and do not necessarily match the scales of social and economic demands, scientific analysis, and governmental or management responses. Scale sensitivity is thus vital and scale-sensitive drivers may require scale-sensitive policies in order to properly address their impacts on biodiversity. On the other hand, the lack of scale sensitivity requires other types of management tools and policy-making approaches.

Understanding how drivers of change, especially anthropogenic ones, operate and interact at various scales, whether they fit the scales at which organisms and ecosystems function, and the development of policy and management approaches on matching scales remain major challenges in biodiversity conservation. The EU project SCALES (Securing the Conservation of biodiversity across Administrative Levels and spatial, temporal, and Ecological Scales), which started in May 2009 and will run for at least five years, has been set up to tackle some of these challenges. It combines the expertise of 27 research teams from 18 European countries and Australia. Here we present the objectives and explain the main approaches of this project. ${ }^{1}$

\section{SCALES' Objectives}

The general aim of SCALES is to improve our understanding of the scale sensitivity of drivers and pressures of biodiversity, biological patterns and processes, and policy instruments as a basis for better fostering our capacity for biodiversity conservation across spatial and temporal scales. This general aim is broken down into seven complementary objectives, to:

1. assess the scale sensitivity of anthropogenic driving forces and the resulting environmental pressures affecting European biodiversity under present and projected future conditions;

2. analyse the scale-dependent impacts of these drivers and pressures on components of biodiversity ranging from genes via populations and biotic communities to ecosystems;

3. develop and evaluate new methods for up- and down-scaling to facilitate the matching of environmental, ecological, and socio-economic information at relevant scales;

4. assess the scale sensitivity and scale effectiveness of existing policy instruments, identify innovative policy instruments to address scale-related conservation problems, and improve multi-level biodiversity governance;

5. test and evaluate the practical suitability and scale matching of selected methods and policy instruments in case studies, using networks of protected areas, regional connectivity, and monitoring of status and trends as a common testing and assessment platform;

6. translate the results into policy and management recommendations and integrate them in a web-based support tool kit for effective biodiversity conservation across scales;

7. disseminate the results to a wide range of relevant policy makers, biodiversity managers, scientists, and the general public and implement effective science-policy interfaces and stakeholder engagement processes.

1 For more information see $\underline{w w w . s c a l e s-p r o j e c t . n e t .}$ 


\section{SCALES' Research Approach}

SCALES is structured into seven thematic work packages (WPs), which reflect the main objectives of the project, plus an additional WP for coordination and management (see figure). The basic approach is to analyse and model the scaling properties of anthropogenic and natural drivers and pressures (climate change, habitat loss and fragmentation, and disturbance), their interactions, and their impacts on biodiversity in parallel to the scale sensitivity of policy responses and instruments. The project is developing new methods and approaches for up- and down-scaling of information collected at various scales and innovative policy instruments to address scale mismatches. It also is evaluating the need of further coordination of multi-level governance. SCALES is integrating these assessments and testing the practical suitability and scale matching of promising approaches, methods, and policy instruments with case studies in Greece, Finland, France, Poland, and the UK. Area requirements for viable populations are being determined, and critical dispersal distances are being defined to ensure connectivity for species that operate at different scales. Habitat patches critical for regional connectivity are being identified. SCALES further focuses on biodiversity assessment and monitoring, and on the coherence and ecological sufficiency of networks of protected areas that account for different conservation responsibilities from the EU to the regional level. Assessment results, methods, and management support tools are being made available on an Internet portal ${ }^{1}$ and the results are being regularly fed into science-policy dialogues.

\section{Understanding Anthropogenic and Natural Processes across Scales}

Socio-economic drivers of change operate at various administrative levels and temporal scales in an interactive way but their interactions and scale-dependency have rarely been examined in combination (Nelson et al. 2006). The same applies for the pressures on biodiversity generated by these drivers. SCALES is analysing how these interactions and non-linearities of anthropogenic processes change across different administrative levels (from regional to EU). EUROSTAT data on indicators of drivers, CORINE land cover data, and the Natura 2000 database of the European Environmental Agency are the main data sources used since they are the common currency of valuable and harmonised data for EU member states. SCALES is assessing whether, and if so, which drivers and pressures explain species distributions and species composition at different spatial scales.

SCALES specifically focuses on three main pressures: climate change, habitat loss and fragmentation, and disturbance. Climate change takes place at global scales, while it affects species distributions, dispersal, performance, and interactions at multiple scales and in interaction with other drivers (Schweiger et al. 2010). For instance, its effects may interact with habitat fragmentation, when habitat specialists and weak dispersers are particularly prone to decline even when large-scale suitable climate space increases, as they may lose current local-scale habitat without be-

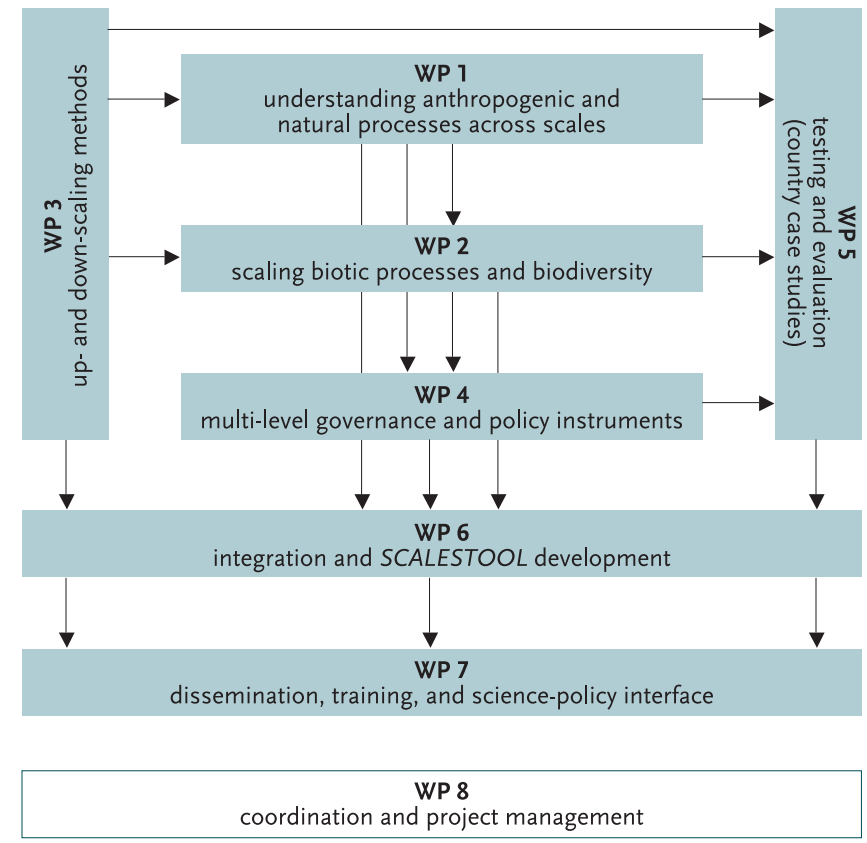

FIGURE: The EU project SCALES (Securing the Conservation of biodiversity across Administrative Levels and spatial, temporal, and Ecological Scales): work plan and interdependencies of the work packages (WPs). Arrows signify input provided by work packages to other work packages.

ing able to disperse into newly suitable sites (Hill et al. 2001). Climate change will also affect spatial distribution patterns of growing populations (e.g., at the expanding range margin) quite differently to shrinking populations (e.g., at retreating range margins) (Wilson et al. 2004). SCALES is assessing whether evidence for climate change impacts - and their interactions with other drivers - can be extracted from distributional patterns at different spatiotemporal scales (Walther et al. 2009). It is modelling the effect that the dispersal power of a species has on its ability to track climatic changes.

Habitat loss and fragmentation affect biodiversity at all levels of biological organisation, from genetic variability (Hoehn et al. 2007) to dispersal and population viability (Clobert et al. 2001, Henle et al. 2004, Kuussaari et al. 2009), community composition (Davies et al. 2000, Schweiger et al. 2005), species trait composition (Öckinger et al. 2010), and ecological function (Potts et al. 2010). They frequently produce synergistic effects with disturbance (Laurance and Cochrane 2001). Recent theoretical and empirical work has shown that the scaling of disturbance and fragmentation in space and time interact with dispersal-related and other species traits to determine the survival of species in fragmented landscapes (Clobert et al. 2009). SCALES is analysing which factors influence local extinction in space and time, whether these extinctions are correlated whith each other, how correlations change with dispersal patterns, and how such processes interact with other species traits. The resulting effects on genetic variability, population viability, community composition, and selected ecosystem functions are being assessed. 


\section{Scaling of Biotic Processes and Biodiversity}

Biological processes are hierarchically structured and in turn interact with the physical environment at a wide range of spatial and temporal scales. The SCALES project is considering the effects of environmental pressures on biological patterns and processes at levels of biological organisation ranging from genetic diversity within species, through the scaling of populations and their viability, up to the scale dependence of species diversity, community composition, and ecosystem functions. These analyses collectively rely on databases of biological traits of species, especially dispersal characteristics and area requirements, which are being compiled by SCALES or are available from other projects. Ultimately, our goal is to bring together these different levels of biotic organisation (genetic, population, community, and ecosystem perspectives) to forge a general understanding of the role of spatial and temporal scale in conservation biology, including reserve network design principles. In pursuit of this goal, SCALES is conducting both comprehensive, but necessarily less intensive, empirical and modelling studies across wide taxonomic groups, as well as intensive studies of a few focal species as exemplars to test the accuracy and to validate the less detailed analyses. The focus on birds, amphibians, reptiles, butterflies, carabid beetles, bees, wasps, and vascular plants allows us to examine biodiversity scaling for species differing greatly in body size and mobility, and crucially in the availability of good quality data. Thus the project will have to evaluate the effectiveness and suitability of methods for both comprehensively mapped taxa and taxa with less complete distributional data.

\section{Up- and Down-Scaling Methods}

As our understanding of the scaling properties of populations and communities has progressed, there are increasing possibilities of translating information across scales. In principle, there is an asymmetrical relationship between maps at different scales: it is a simple matter to produce a coarse-resolution map from finerscale information, but fine-scale maps require more information than coarse ones, making accurate and reliable down-scaling impossible (Rocchini et al. in press). Nevertheless, there is increasing evidence that some vital fine-scale information (e.g., overall occupancy or abundance) can be estimated from coarse-scale maps (Kunin 1998, Hui et al. 2009), but no single consensus method has yet emerged. SCALES is testing and improving competing methods using taxa that are well mapped at various scales.

Up-scaling information from point samples faces different challenges. Many issues in biodiversity conservation require information at spatial scales (national, continental, and global) too coarse to be surveyed effectively on an ongoing basis. As a consequence, these data are highly heterogeneous in nature and their integration requires advanced statistical methodologies (Henry et al. 2008, Lengyel et al. 2008). Recent work (Ugland et al. 2003, Harte et al. 2009) also suggests a novel possibility for community level assessments: building up estimates of species-area relationships from scattered point biodiversity samples. SCALES is extending these recent methodological developments for infer- ring coarse-scale biodiversity assessments from point estimates. The project is developing uncertainty models, including multilevel statistical models, to scrutinise results from such analyses.

Cross-scale assessment methods are particularly important for multi-scale conservation prioritisation since European-wide conservation priorities are not always fully convergent with national ones. As a consequence, different countries have developed novel priority setting tools (Brooks et al. 2006), among them the concept of national responsibilities (Schmeller et al. 2008 a). Only recently, a freely scalable method to determine national responsibilities for the conservation of species has been developed (Schmeller et al. 2008b). SCALES is applying this method to selected taxonomic groups and is expanding the ZONATION software for optimisation of networks of protected areas (Moilanen 2007) to allow coverage of multiple administrative levels with different conservation priorities.

Monitoring of species and habitats of conservation concern is fundamental to the design and evaluation of biodiversity conservation measures (Lengyel et al. 2008). SCALES is developing recommendations for improving monitoring schemes so that data can be used to address conservation issues across scales (from local protected areas to the impact of fragmentation and climate change on biodiversity at a global scale) by reviewing and evaluating cross-scale species monitoring methods. Based on existing species distribution data (collected using intensive monitoring schemes, such as the French breeding bird survey, STOC; Julliard et al. 2003), the efficiency of existing scalable monitoring schemes is being evaluated.

\section{Multi-Level Governance and Policy Instruments}

The negative impacts of anthropogenic and natural drivers and pressures on biodiversity across scales are also recognised at the policy level (MEA 2005). ${ }^{2}$ However, the policies adopted at different administrative levels might not be matched to the relevant ecological scales and thus may generate unintended negative effects (Cumming et al. 2006). Therefore, there is a need to strengthen our understanding of the scale effectiveness and sensitivity of policy instruments, policy mixes, and administrative practices. Although the current EU-level policy framework is of utmost importance, the implementation of EU policies operates as a multi-level governance process, which makes policy implementation more context-relevant, but also creates discontinuities and problems (Fairbass and Jordan 2004, Similä et al. 2006). The final outcomes of EU policies critically depend on national institutions and practices, which are affected by - but not necessarily determined by - the EU. For example, due to differences in national nature conservation traditions, the human activities allowed in Natura 2000 areas vary greatly from country to country (European Commission 2004, Marquart-Pyatt 2007).

In multi-level governance, no single instrument or level is likely to be effective alone. Hence, attempts to improve the capacity

2 See also www.teebweb.org. 
of policies to deal with scale-related problems must put special emphasis on the interaction between and within different administrative levels and across sectors in various national settings. In particular, effective biodiversity governance has to consider spatial scale relations (Ring 2008). However, the spatial characteristics of economic, social, and environmental costs and benefits of biodiversity conservation and biodiversity-related public goods and services do not always match with governmental levels or jurisdictional boundaries, nor with the scales of relevant biological processes.

SCALES is tackling these challenges by studying policy instruments and policy mixes on various levels from a multi-level governance perspective. Both biodiversity conservation instruments, such as the Habitats Directive (92/43/EEC) ${ }^{3}$, as well as instruments relevant for regional connectivity, such as agri-environmental schemes and land use planning, are being assessed at various administrative levels. These analyses are undertaken in relation to relevant trends and constraints, to identify broad policy and legal frames within which any reform related to nature conservation policy will eventually take place. This will facilitate the adoption of policy recommendations originating from the analyses.

SCALES is further identifying and developing innovative policy instruments to address and resolve mismatches between different scales. An example of this type of instrument is the integration of conservation-related indicators into inter-governmental fiscal transfers from higher (EU, national, or state) to lower (regional or local) administrative levels (Köllner et al. 2002, Ring 2002). By reviewing international experiences and building on the recently amended Portuguese community financing law (January 2007), which for the first time in Europe introduced the designation of Natura 2000 sites and other protected areas as a possible precondition for fiscal transfers to municipalities (Prates 2008), SCALES is exploring options for transferring these policies to other European countries. Further examples being investigated are the public participatory approaches to the design of conservation policies and the involvement of non-governmental organisations in Natura 2000 monitoring, also referred to as citizen-science based schemes for monitoring (Cent et al. 2007, Bell et al. 2008, Schmeller et al. 2009).

\section{Testing and Evaluation (Country Case Studies)}

SCALES is testing and evaluating combinations of assessment methods and policy instruments developed and explored in other parts of the project, with a focus on scale matching and practicability to support the conservation of biodiversity at various scales given real world constraints. SCALES has selected three major fields within applied biodiversity conservation for testing: coherence and ecological sufficiency of networks of protected areas across administrative levels, regional connectivity, and monitoring of conservation status and trends of biodiversity. Testing will be conducted at scales ranging from regional to Europe. At the national scale, five countries (Greece, Finland, France, Poland, UK) have been selected to represent ecological and societal variability as well as differences in biodiversity conservation history and decision-making approaches. The following criteria are currently considered for evaluation: applicability of the approaches to existing data, especially non-standard maps and datasets; degree of understanding and uncertainty of insights gained; efforts, skills, and training required; acceptance by managers of biodiversity and natural resources; and scale matching between assessment methods and policy instruments.

An example of mismatch that is being examined is the lack of ecological information at the relevant scale in the planning of corridors such as ECONET in Poland. In Poland, like in most countries, ecological connectivity is strongly enforced by national law and included in regional plans. However, regional plans are usually not supported by ecological guidelines on species needs of corridors at the regional scale and this practically results in the use of local strategies based on informal rules, experience, and knowledge of stakeholders (Jȩdrzejewski 2009). When ecological information enters only at the local level, there is a high risk that areas important for the dispersal of large mobile species, such as lynx, wolf, or otter, are not included in the system of regional corridors. This in turn can make the corridor system ineffective.

\section{Integration and SCALESTOOL Development}

Results from research projects are usually scattered throughout the literature. This greatly hampers the uptake of the generated knowledge to support effective conservation of biodiversity, especially when different scales need to be taken into consideration. As a consequence, some major advances in natural sciences have seen limited or inadequate application in the policy arena. Likewise, principles of policy instrument design, as well as constraints of biodiversity management and policy processes, are insufficiently accounted for by natural science. An example is the mismatch of methodological developments in systematic reserve site planning, policy instruments, and management realities (Knight 2006), and Europe is no exception to these potential mismatches.

SCALES is using an interdisciplinary approach linking the social and natural sciences to match advances in ecological understanding with improvements in policy instruments (especially in the case studies). This provides the basis for translating the project results into recommendations for policy and management in a coherent framework. Five modules are envisioned for the framework, targeting understanding of inter-linkages between drivers and pressures affecting biodiversity at various scales, coherence and ecological sufficiency of networks of protected areas, regional connectivity, monitoring of conservation status and trends in biodiversity, and relevant combinations of policy instruments (i.e., responses) to manage biodiversity at appropriate scales. The monitoring module is an extension of the BioMAT tool developed by the EuMon project ${ }^{4}$. The framework is being delivered as a webbased support tool kit called the SCALESTOOL.

\footnotetext{
3 http://ec.europa.eu/environment/nature/legislation/habitatsdirective/ index_en.htm

4 http://eumon.ckff.si/biomat
} 


\section{Dissemination, Training, and Science-Policy Interface}

SCALES has adopted open access and multi-targeted popularisation of outputs as its basic dissemination principle. SCALES therefore is responding to the decision of the Council of Europe that 20 percent of the scientific papers produced from projects within the Seventh Framework Programme (FP7) must be deposited in an ISO-certified open access repository six to twelve months after publication. Open access is guaranteed via the Internet portal of $S C A L E S^{1}$, which provides structured access to results targeting three main user groups: 1 . policy, administration, conservation managers; 2 . scientists; 3 . journalists, the general public. SCALES is establishing a new open access online scientific journal based on the innovative concept of Open Access Triade ${ }^{\mathrm{TM}}$ combining three important ways of distributing scientific results: science publishing, popular-science newsletter, and online archive (SCALES Online Library) of scale-related papers.

Experience has shown that it usually takes a very long time for results of research projects to be integrated into conservation policy and application. Such integration is of crucial importance to ensure stakeholder input into strategic research. A systematic science-policy dialogue is essential to catalyse these processes (Van den Hove 2007). This is a particular challenge to research projects because of their limited duration and because, in the case of EU projects, they have to target different administrative levels. Therefore, we made sure in the preparation of the project that individuals with well-established involvements in science-policy interfaces at the local-regional, national, or EU level were participating. $S C A L E S$ also is closely collaborating with existing science-policy interfaces, such as the European Platform for Biodiversity Research Strategy and the Intergovernmental Science-Policy Platform on Biodiversity and Ecosystem Services (IPBES) (Görg et al. 2010, in this issue), and has included among others representatives of the Directorate General Environment of the European Commission, the European Topic Centre for Biodiversity, the European Environment Agency, and the World Conservation Monitoring Centre of the United Nations Environment Programme (UNEP-WCMC) in its Advisory Board. In this way, SCALES has fostered sciencepolicy exchange from the very beginning of the project. For example, the first interim results of SCALES (Settele and Kühn 2009) were presented soon after its start as part of an ALARM presentation (Settele et al. 2005) at the European Parliament. SCALES has a specific budget allocated to support stakeholder engagement processes, including joint workshops, throughout the project and at various scales from local to Europe.

Finally, SCALES includes a range of training activities, which aim to teach and provide key skills to managers and young scientists in the fields of biodiversity assessment and modelling, and help them communicate with various stakeholders.

\section{Outlook}

While accounting better for scales in biodiversity policy and management is not a panacea for solving all conservation problems, we firmly believe that a better match of the scales of policy and management to the scale of biological processes will make biodiversity conservation much more effective without exceeding the current level of efforts. We hope that our article contributes to creating more awareness of scale mismatches and of approaches that may be suitable to resolve them.

SCALES is funded by the European Commission as a Large-scale Integrating Project within FP 7 under grant 226852 . We thank all our partners in the SCALES project for contributing to the design of the project.

\section{References}

Altmoos, M., K. Henle. 2010. Relevance of multiple spatial scales in habitat models: A case study with amphibians and grasshoppers. Acta Oecologica. doi:10.1016/i.actao.2010.08.001.

Behrens, V., F. Rauschmayer, H. Wittmer. 2008. Managing international 'problem' species: Why pan-European cormorant management is so difficult. Environmental Conservation 35: 55-63.

Bell, S. et al. 2008. What counts? Volunteers and their organizations in the recording and monitoring of biodiversity. Biodiversity and Conservation 17: $3443-3454$.

Brooks, T. M., R. A. Mittermeier, G. A. B. da Fonseca, J. Kent. 2006. Global biodiversity conservation priorities. Science 313: 58-61.

Cent, J., H. Kobierska, M. Grodzińska-Jurczak, S. Bell. 2007. Who is responsible for Natura 2000 in Poland? A potential role of NGOs in establishing the program. International Journal of Environment and Sustainable Development 6: $422-435$.

Clobert, J., J. D. Nichols, E. Danchin, A. Dhondt. 2001. Dispersal. Oxford, UK: Oxford University Press.

Clobert, J., J.-F. Le Galliard, J. Cote, S. Meylan, M. Massot. 2009. Informed dispersal, heterogeneity in animal dispersal syndromes and the dynamics of spatially structured populations. Ecology Letters 12: 197-209.

Cumming, G.S., D. H. M. Cumming, C. L. Redman. 2006. Scale mismatches in social-ecological systems: Causes, consequences, and solutions. Ecology and Society 11: 14-33.

Davies, K. F., C. R. Margules, J. F. Lawrence. 2000. Which traits of species predict population declines in experimental forest fragments? Ecology 81: 1450-1461.

Debinsky, D. M., C. Ray, E.H. Saveraid. 2001. Species diversity and the scale of the landscape mosaic: Do scales of movement and patch size affect diversity? Biological Conservation 98: 179-190.

European Commission. 2004. Life-nature: Communicating with stakeholders and the generic public. Best practice examples for Natura 2000. Luxembourg Office for Official Publications of the European Communities.

Fairbass, J., A. Jordan. 2004. Multi-level governance and environmental policy. In: Multi-level governance. Edited by I. Bache, M. Flinders. Oxford, UK: Oxford University Press. 147-164.

Görg, C., C. Neßhöver, A. Paulsch. 2010. A new link between biodiversity science and policy. GAIA 19/3: 183-186.

Harte, J., A. B. Smith, D. Storch. 2009. Biodiversity scales from plots to biomes with a universal species-area curve. Ecology Letters 12: 789-797.

Hartley, S., W. E. Kunin. 2003. Scale dependency of rarity, extinction risk, and conservation priority. Conservation Biology 17: 1559-1570.

Henle, K., C. Bender, K. Schmidt-Loske, U. Asmussen. 1999. PVAs in der Eingriffsplanung am Beispiel der Flurbereinigung von Weinbergen. In: Populationsbiologie in der Naturschutzpraxis. Isolation, Flächenbedarf und Biotopansprüche von Pflanzen und Tieren. Edited by K. Amler, A. Bahl, K. Henle, G. Kaule, P. Poschlod, J. Settele. Stuttgart: Ulmer. 241-248.

Henle, K., K. F. Davies, M. Kleyer, C. Margules, J. Settele. 2004. Predictors of species sensitivity to fragmentation. Biodiversity and Conservation 13: 207-251.

Henle, K. et al. 2008. Identifying and managing the conflicts between agriculture and biodiversity conservation in Europe $-\mathrm{A}$ review. Agriculture Ecosystems and Environment 124: 60-71.

Henry, P.-Y. et al. 2008. Integrating ongoing biodiversity monitoring: Potential benefits and methods. Biodiversity and Conservation 17: 3357-3382. 
Hill, J. K. et al. 2001. Impacts of landscape structure on butterfly range expansion. Ecology Letters 4: 313-321.

Hoehn, M., S. D. Sarre, K. Henle. 2007. The tales of two geckos: Does dispersal prevent extinction in recently fragmented populations? Molecular Ecology 16: 3299-3312.

Hui, C., M. A. McGeoch, B. Reyers, P. C. le Roux, M. Greve, S. L. Chown. 2009. Extrapolating population size from the occupancy-abundance relationship and the scaling pattern of occupancy. Ecological Applications 19: 2038-2048.

Jesdrzejewski, W. 2009. The network of ecological corridors connecting the protected areas in Poland. In: Ochorna łączności ekologicznej Polski. Edited by W. Jȩdrzejewski, D. Ławreszuk. Białowieża, PL: Zakład Badania Ssaków Polskiej Akademii Nauk. 71-82 (in Polish).

Julliard, J., F. Jiguet, D. Couvet. 2003. Common birds facing global changes: What makes a species at risk? Global Change Biology 10: 148-154.

Knight, A.T. 2006. Failing but learning: Writing the wrongs after Redford and Taber. Conservation Biology 20: 1312-1314.

Köllner, T., O. Schelske, I. Seidl. 2002. Integrating biodiversity into intergovernmental fiscal transfers based on cantonal benchmarking: A Swiss case study. Basic and Applied Ecology 3: 381-391.

Kunin, W. E. 1998. Extrapolating species abundance across spatial scales. Science 281: 1513-1515.

Kuussaari, M. et al. 2009. Extinction debt: A challenge for biodiversity conservation. Trends in Ecology and Evolution 24: 564-571.

Laurance, W. F., M. A. Cochrane. 2001. Synergetic effects in fragmented landscapes. Conservation Biology 15: 1488-1489.

Le Gallo, J., C. Ertur. 2003. Exploratory spatial data analysis of the distribution of regional per capita GDP in Europe, 1980-1995. Papers in Regional Science 82: 175-201.

Lengyel, S. et al. 2008. A review and a framework for the integration of biodiversity monitoring at the habitat level. Biodiversity and Conservation 17: 3341-3356.

Lepart, J., P. Marty. 2005. La mise en oeuvre du réseau Natura 2000: Questions à l'écologie scientifique. In: Natura 2000. De l'injonction européenne aux négociations locales. Edited by J. Dubois, S. Maljean-Dubois. Paris: La Documentation Française. 27-44.

Marquart-Pyatt, S. T. 2007. Concern for the environment among general publics: A cross-national study. Society and Natural Resources 20: 883-898.

Mathevet, R., A. Mauchamp. 2005. Evidence-based conservation: Dealing with social issues. Trends in Ecology and Evolution 20: 422-423.

MEA (Millennium Ecosystem Assessment). 2005. Ecosystems and human well-being. Synthesis report. Washington, D. C.: Island Press.

Moilanen, A. 2007. Landscape zonation, benefit functions and target-based planning. Unifying reserve selection strategies. Biological Conservation 134: $571-579$.

Nelson, G. C. et al. 2006. Anthropogenic drivers of ecosystem change: An overview. Ecology and Society 11/2: 29 (online). www.ecologyandsociety.org/vol11/iss2/art29.

Öckinger, E. et al. 2010. Life-history traits predict species responses to habitat area and isolation - A cross-continental synthesis. Ecology Letters 13: 969-979.

Potts, S. G., J. C. Biesmeijer, C. Kremen, P. Neumann, O. Schweiger, W. E. Kunin 2010. Global pollinator declines: Drivers and impacts. Trends in Ecology and Evolution 25: 345-353.

Prates, J. C. A. 2008. As finanças locais e a promoção da conservação da natureza. Dissertação apresentada na Faculdade de Ciências e Tecnologia da Universidade Nova de Lisboa para obtenção do grau de Mestre em Engenharia do Ambiente, perfil Gestão e Sistemas Ambientais. Lisbon.

Ring, I. 2002. Ecological public functions and fiscal equalisation at the local level in Germany. Ecological Economics 42: 415-427.

Ring, I. 2008. Biodiversity governance: Adjusting local costs and global benefits. In: Public and private in natural resource governance: A false dichotomy? Edited by T. Sikor. London: Earthscan. 107-126.

Rocchini, D. et al. In press. Accounting for uncertainty when mapping species distributions: The need for maps of ignorance. Progress in Physical Geography.

Schmeller, D. S., B. Gruber, E. Budrys, E. Framstad, S. Lengyel, K. Henle. 2008 a. National responsibilities in European species conservation: A methodological review. Conservation Biology 22: 593-601.

Schmeller, D. S. et al. 2008 b. Determination of national conservation responsibilities for species in regions with multiple political jurisdictions. Biodiversity and Conservation 17: 3607-3622.
Schmeller, D. S. et al. 2009. Advantages of volunteer-based biodiversity monitoring in Europe. Conservation Biology 23: 307-316.

Schweiger, O. et al. 2005. Quantifying the impact of environmental factors on arthropod communities in agricultural landscapes across organizational levels and spatial scales. Journal of Applied Ecology 42: 1129-1139.

Schweiger, O. et al. 2010. Multiple stressors on biotic interactions: How climate change and alien species interact to affect pollination. Biological Reviews. doi: 10.1111/j.1469-185X.2010.00125.x

Settele, J. et al. 2005. ALARM - Assessing LArge-scale environmental Risks for biodiversity with tested Methods. GAIA 14/1: 69-72.

Settele, J., E. Kühn. 2009. Insect conservation. Science 325: 41-42.

Similä, J., R. Thum, R. Varjopuro, I. Ring. 2006. Protected species in conflict with fisheries: The interplay between European and national regulation. Journal of European Environmental and Planning Law 5: 432-445.

Steinicke, H., K. Henle, H. Gruttke. 2002. Bewertung der Verantwortlichkeit Deutschlands für die Erhaltung von Amphibien- und Reptilienarten. Bonn: Bundesamt für Naturschutz.

Ugland, K. I., J. S. Gray, K. E. Ellingsen. 2003. The species-accumulation curve and estimation of species richness. Journal of Animal Ecology 72: 888-897.

Van den Hove, S. 2007. A rationale for science-policy interfaces. Futures 39: 807-826.

Walther, G. R. et al. 2009. Alien species in a warmer world: Risks and opportunities. Trends in Ecology and Evolution 24: 686-693.

Wilson, R. J., C. D. Thomas, R. Fox, D. B. Roy, W. E. Kunin. 2004. Spatial patterns in species distributions reveal biodiversity change. Nature 432: 393-396.

Submitted April 15, 2010; revised version accepted September 24, 2010.

\section{Klaus Henle}

Born 1955 in Waiblingen, Germany. MSc in biology from the University of Stuttgart-Hohenheim, Institute of Zoology; $\mathrm{PhD}$ in zoology, Australian National University, Canberra; habilitation in zoology, University of Mainz, Germany. Head of the Department of Conservation Biology at the Helmholtz

Centre for Environmental Research - UFZ, Leipzig. Coordinator of international research projects in conservation biology. Research interests: conservation biology, especially habitat fragmentation and monitoring of biodiversity.

\section{Simon G. Potts}

Born 1969 in Manchester, UK. BA in biology, University of Oxford, UK. PhD in ecology, St Andrews University, UK. Postdoctoral research fellow at Haifa University, Israel, and St Andrews University. Senior research fellow and principal research fellow, University of Reading, UK.

Research interests: understanding the effects of environmental change on biodiversity, ecosystem function, and ecosystem services; providing high quality scientific evidence for the development of management practices and policies for adaptation and mitigation.

\section{Małgorzata Grodzińska-Jurczak}

Born 1966 in Kraków, Poland. MSc in environmental biology, $\mathrm{PhD}$ in environmental sciences, habilitation in environmental education, all at Jagiellonian University, Kraków. Associate Professor, lecturer, and leader of the Nature Protection and Environmental Education Research Team at the Institute of Environmental Sciences, Jagiellonian University. Consultant to national/international educational projects. Research interests: human dimension approach to natural resource management, environmental education. 